\title{
Gençlerin Tüketici Olarak Sosyalleşmesinde Sosyal Medyanın Etkisi
}

\author{
DOI: 10.26466/opus.535049 \\ * \\ $\underline{\text { Kumru Uyar* }}$ \\ *Dr, Öğr. Üyesi, Nuh Naci Yazgan Üniversitesi, İ̈BF, Kocasinan / Kayseri / Türkiye \\ E-Posta: kuyar@nny.edu.tr \\ ORCID: 0000-0002-2604-5317
}

\section{Öz}

Bilişim teknolojilerinin gelişmesiyle iletişim yepyeni bir boyut kazanmıştır. Sosyal ă̆ tabanlı uygulamalar yaşamımızın her alanında kullanılmaktadır. Bu etki tüketici davranışlarında da görülmektedir. Bu araştırmanın amact, sosyal medyaya maruz kalma ve cinsiyete göre tüketici sosyalleşme aracılarının (aile, akran, marka, sosyal medya) farklılık gösterip göstermediğini tespit etmektir. Ergenler sosyal etkilere daha açık olabileceği için çalışma orta öğrenim öğrencilerine uygulanmıştır. Çalışmada kullanılan ölçekler Dotson ve Hyatta (2005) çalışmalarından uyarlanmıştır. Veriler kolayda örnekleme yöntemi ile seçilen 347 katılımcıdan anket yöntemi ile toplanmıştır. Analizlerde SPSS 22 paket programı kullanılmıştır. Elde edilen bulgulara göre cinsiyete göre akran ve aile etkisi farklılık göstermektedir. Kızlarda bu iki aracının etkisi daha yüksekken erkeklerde daha düşüktür. Ancak cinsiyete göre marka ve sosyal medyaya maruz kalmanın etkisi istatistiksel olarak anlamlı bir farklılık göstermemektedir. Ayrıca, sosyal medyaya maruz kalma düzeyleri açısından ise marka ve sosyal medyanın etkisinin farklılık gösterdiği tespit edilmiştir. Ancak sosyal medyaya maruz kalma düzeyleri açısından aile ve akran etkisinin farklılık göstermediği görülmüştür. Çalışmanın, aile, akran, marka ve sosyal medya gibi tüketici sosyalizasyon aracılar literatüründeki ana bulguların güncelleyerek ve tüketici sosyalleşme sürecinin günümüz gençlerinde nasıl çalıştığını açıklama yönünde ampirik bir bilgi sağlayarak literature katkı să̆laması beklenmektedir.

Anahtar Kelimeler: Tüketici Sosyalleşme Süreci, Sosyal Medya, Sosyalleşme Aracıları, Ergenlik 


\title{
The Impact of Social Media on Youth Socialization
}

\begin{abstract}
With the development of Information Technologies, communication has gained a whole new dimension. Social networking applications are used in every aspect of our lives. This effect is also observed in consumer behaviors. The aim of this article is to determine whether consumer socialization agents (family, peer, brand, social media) differ according to social media exposure and gender. Because adolescents may be more open to social impacts, the study was applied to secondary school students. The scales used in the study were adapted from Dotson and Hyatta (2005) studies. The data were collected by 347 participants selected by means of sampling method. SPSS 22 package program was used in the analysis. According to the findings, peer and family effect per gender is different. The effect of these two tools for girls is higher than for boys. However, the effect of exposure to brand and social media by gender does not show a statistically significant difference. In addition, the effect of brand and social media on social media has been found to be different in terms of exposure levels. Nevertheless, family and peer effects did not differ in terms of exposure to social media. The study is expected to contribute to the literature by updating the main findings in the literature of consumer socialization agents such as family, peer, brand and social media and providing empirical information to explain how the consumer socialization process works in today's youth.
\end{abstract}

Keywords: Consumer Socialization Process, Social media, Agents of Socialization, Puberty. 


\section{Giriş}

Sosyal medya kullanımındaki hızlı artış, sosyal medyanın yeni bir pazarlama aracı olarak tanımlanmasının yolunu açmıştır. Sosyal medya reklamcılığı medya karmasının önemli bir parçası haline gelmiştir. İşletmeler bu yeni mecra ile tüketicilere doğrudan ve kişiselleştirilerek daha düşük maliyetle ulaşabilmektedir. Bu sebeple sosyal medya, işletmelerin potansiyel müşterilerine ulaşmada elde ettikleri oldukça yeni ve güçlü bir pazarlama kanalı olarak tanımlanabilir. Böylece sosyal medya tüketici olarak sosyalleşme sürecinde etkili bir araç olarak karşımıza çıkmaktadır. Çocuk ve genç pazarının dinamiklerinde günümüzde çarpıcı gelişmeler olmuştur. Gençlerin geleneksel bilgi kaynakları olan ve tüketim kararlarını etkileyen aile, akran ve geleneksel medyaya ek olarak günümüzde sosyal medya ağları da önem kazanmıştır. İnsan bil-gisayar etkileşimi (Human computer interaction, HCI) özelliği yüksek sosyoteknolojilerin kullanım kolaylığı ve heyecan verici görünümü çocukları ve gençleri cezbetmektedir. HCI özellikli teknolojilerle sosyal medyayı çok kolay kullanabilen çocuklar ve gençler, Youtube, Facebook, Instagram gibi sosyal medya platformlarına kolayca dahil olarak sosyalleşebilmekte ve bu platformlarda gördükleri reklamlar karşısında güçlü potansiyel tüketiciler olabilmektedirler. Bunlara ek olarak, artık neredeyse her platformda karşımıza çıkan yapay zeka algoritmaları sayesinde, çocuklar ve gençlere hitap edecek görsel reklamlar kendilerine herhangi bir cihaz üzerinde sunulmaktadır.

Özellikle internet kullanımının artması, sosyal medya ile medya kullanımının farklılaşması ve aile yapısındaki sosyolojik değişikliklere bağlı olarak tüketici sosyalleşme süreci günümüzde çok farklılaşmıştır. Gençler aile satın alma karar sürecinin her aşamasında giderek daha fazla etkili olmaktadırlar (Uyar, Güllü, ve Erkan, 2015). Bu açıdan tüketici sosyalleşme süreçleriyle ilgili daha yeni araştırmaların yapılarak geleneksel varsayımlarının yeniden gözden geçirilmesi önerilmektedir (Dotson ve Hyatt, 2005, s. 36). Bu çalışmada, tüketici sosyalleşme sürecinde sosyal medya etkileyici bir kaynak olarak incelenmektedir. Genç tüketiciler üzerinde bir etki kaynağı olarak sosyal medyayı dikkate alan bir çalışmaya Türkçe literatürde rastlanmamıştır. Oysa sosyal medya gençlerin tüketim davranışlarında oldukça etkilidir. Son araştırmalar, 
gençlerin sosyal medyada, reklamlara maruz kalmalarını artıran önemli miktarda zaman harcadıklarını göstermektedir (Vijayalakshmi, Lin, ve Laczniak, 2018, s.595). Ayrıca çalışmada akran ve aile etkisi de incelenmiştir. Aile ve akranlar kişilerarası ilişkilerin ve davranışlarının oluşumunu önemli ölçüde etkilemektedir. Ergenlik çağ1 sosyalleşmedeki en önemli zamandır (Niu, 2013). Bu sebeple çalışma sadece orta öğrenim öğrencileri ile sınırlı tutulmuştur.

Yabancı literatürde sosyalleşme aracıları ile sosyal medyaya arasındaki ilişkiyi inceleyen sınırlı sayıda ampirik çalışma yer almaktadır. Türkçe literatürde de çalışmaların büyük bir kısmı tüketicilerin sosyalleşme süreçlerini kavramsal olarak incelemişlerdir (Ateşoğlu ve Türkkahraman, 2009; Dal ve Dal, 2015; Madran ve Bozyiğit, 2013). Sosyal medya ile tüketici sosyalleşme süreci arasındaki ilişkiye odaklanan az sayıda ampirik çalışma yer almaktadır (Balıkçığlu ve Volkan, 2016; Südaş ve Töre 2015). Bu çalışmaların ise çok büyük bir kısmı çocukların sosyalleşmesi üzerine odaklanmıştır (Bozyiğit ve Madran, 2018). Literatürde birkaç ampirik çalışmada ergenler dikkate alınmıştır (Balıkçıŏlu ve Volkan, 2016; Dursun, 1993; Südaş ve Töge, 2015). Bu açıdan çalışma önem arz etmektedir. Bozyiğit ve Madran, (2018) çalışmalarında farklı çocuk yetiştirme tutumlarına sahip annelerin, çocuklarının (4-6 yaş) tüketim davranışını nasıl şekillendirdiğini ortaya çıkartmayı amaçlamışlardır.

Gençlerin sosyal medya ile kurdukları bağ yadsınamaz. Günümüzde gençler her türlü sosyal ve tüketimle ilgili ihtiyaçlarını sosyal medya üzerinden karşlayabilmektedirler. Sosyal medya adeta günlük hayatlarının bir parçasıdır. Bu açıdan sosyal medyanın gençlerin tüketici olarak sosyalleşmesine etki edip etmemesinin tespiti önemli bir sorundur. $\mathrm{Bu}$ araştırmanın temel amacı, bu soruna cevap bulmaktır. Bu amaçla, öncelikle gençlerin sosyal medya kullanım davranışlarını tespit etmek, sonrasında ise Türkiye'deki gençlerin tüketici sosyalleşme sürecinin nasıl işlediğine dair ampirik bir açıklama sunmaya çalışılmaktadır. Bu doğrultuda çalışmada, cinsiyete ve sosyal medya kullanımına dayalı sosyalleşme aracılarındaki farklılıklar ele alınmaktadır.

$\mathrm{Bu}$ yazının ana hatları şu şekilde düzenlenmiştir. Kısa giriş bölümünden sonra, konu kavramsal olarak ele alınmıştır. Sonrasında ise veri toplama ve analizini içeren metodoloji bölümü sunulmuştur. Son bölümde 
ise araştırmanın sonuçları tartışılmış ve araştırmanın kısıtları doğrultusunda bu alandaki akademisyen ve araştırmacılara gelecek çalışmaları için önerilerde bulunulmuştur.

\section{Kavramsal Çerçeve}

$\mathrm{Bu}$ bölümde tüketici sosyalleşmesi kavramı ve bu sosyalleşme sürecine etki eden faktörlerle (ebeveynler, akranlar ve sosyal medya) ilgili literatür taraması yapılmaktadır.

\section{Gençlerin Tüketici Olarak Sosyalleşmesi}

Sosyalleşme, bir toplumun veya kültürün mevcut kurallarını, normlarını ve değerlerini öğrenip benimsenmesidir. Sosyalleşme teorisi, genç tüketicilerin alışveriş yapmayı nasıl öğrendiklerini anlamak için ortak bir zemin oluşturmaktadır (Thaichon, 2017, s.39). Pazarlama bağlamında, tüketici sosyalleşmesini Ward (1974, s.2), gençlerin pazarda tüketici olarak varoluşu ile ilgili bilgi, beceri ve tutum kazanma süreçleri şeklinde tanımlanmaktadır.

Tüketici sosyalleşme modeli (Moschis ve Churchill, 1978, s.599), bilişsel gelişim ve sosyal öğrenme teorilerine dayanmaktadır. Bilişsel gelişim teorisi, doğal olgunlaşma (yaş) ve çevresel deneyimlerin öğrenme sürecindeki önemini vurgularken, Bandura'nın (1977) sosyal öğrenme teorisi gözlem, taklit etme veya modelleme yoluyla öğrenmeyi önemser (Mishra, Maheswarappa, ve Colby, 2018). Tüketici sosyalleşme teorisi, iki teoriyi bütünleştirir ve çocukların davranışsal gelişiminin, ebeveynlerinin veya arkadaşlarının ne yaptığını izleyerek öğrendikleri bir olgunlaşma ve gözlem işlevi olduğunu belirtir (Moschis, Moore ve Smith, 1984). Bireysel faktörler, sosyal aracılar ve öğrenme modelleri sonucunda gerçekleşen sosyalleşme süreci sonucunda da çocukta gözlem, talepte bulunma, seçim yapma, yardımlı alışveriş ve bağımsız alışveriş yapabilme gibi davranışlar oluşmaktadır (Madran ve Bozyiğit, 2013, s.91). Tüketici sosyalleşme teorisi, tüketici tutum ve davranışlarının bir tüketici ile dört ana sosyalleşme aracısı arasındaki etkileşim yoluyla çocukluk ve ergenlik sırasında öğrenildiğini ortaya koymaktadır (Harris, Gordon, MacKintosh, ve Has- 
tings, 2015). Sosyalleşme süreci, ebeveynler, akranlar, medya ve okullardan oluşan sosyalleşme aracıları ve yaş ve cinsiyet gibi öncülleri kapsar (Moschis ve Churchill, 1978; Ward, 1974). Bu sosyalleşme araciları çocuklara ve ergenlere normları, tutumları, motivasyonları ve davranışları transfer eden etki kaynakları olarak tanımlanmaktadır (Thaichon, 2017, s.39).

Bazı çalışmalar, ergenlik çağında tüketici olarak sosyalleşmeye etki eden kaynakları ebeveynler, akranlar, kitle iletişim araçları, sosyal medya, mağazalar, okullar, markalar, ürünler ve ambalajlar olarak tanımlamıştır (Fan ve Li, 2010; Südaş ve Töge, 2005; Thaichon, 2017). Medyaya ek olarak, çocuklar ambalajdan ürün bilgisi, akranlardan ve aileden tavsiye alırlar ve kendi tüketici deneyimlerinden ürün özelliklerini öğrenirler. Cowell (2001) tüketici olarak sosyalleşmede etkili olan faktörleri eğitimsel gelişmeyle (ebeveyn ve okul) ve sosyal etkileşimle (akranlar ve televizyon) etkili olanlar olmak üzere ikiye ayırmaktadır. Diğer sosyalleştirme faktörleri ise ailenin dışındaki akrabalar, din grupları ve diğer kitle iletişim araçlarıdır.

Günümüz gençleri günlük yaşamlarında hem çok daha fazla reklama maruz kalırlar, hem de etki kaynaklarıla daha erken yaşlarda çevrelenirler. Ayrıca ebeveynleriyle daha az ve akranlarıyla daha fazla zaman geçiren bu gençler üzerinde popüler markalara yönelik akran baskısı giderek daha fazla artmaktadır (Dotson ve Hyatt, 2005, s. 37).

\section{Ebeveyn:}

Aile, tüketici sosyalleşme sürecini etkileyen en önemli sosyal aracılardan biridir (Basu ve Sondhi, 2014; Thaichon, 2017; Ward, 1974). Aile alışverişine dahil olan çocuklar, bağımsız yetkin tüketiciler olmak için temel becerileri öğrenmeye başlar. Ebeveynleriyle birlikte alışveriş yapmak, çocuklar ebeveynlerinin alışveriş deneyimlerini gözlemleyebildiği ve öğrenebileceği için genellikle sosyalleşmenin kilit bir yöntemi olarak kabul edilir (Thaichon, 2017, s.39). Ebeveynler, tercih edilen bilgi kaynağ haline geldiğinde çocuk ergenliğe ulaşana kadar ebeveynler baskın etki rolü oynamaktadır (Moschis ve Moore, 1980). Ebeveynler, çocuklar üzerindeki rasyonel etkinin ana kaynağıdır; akranlar ve medya öncelikli olarak irrasyonel etkilerdir (Moschis ve Churchill, 1978). Yapılan birçok 
çalışma, tüketimin davranışının çocuklarca öğretilmesinde ailelerinin önemli bir etkisi olduğunu tespit etmiştir. Annenin sosyal statüsü ve ekonomik durumunun (Carlson ve Grossbar, 1988) annenin sosyal statü ve ekonomik durumunun, tam zamanlı çalışmasının (Haynes, Burts, Dukes, ve Cloud, 1993) ve tutumlarının (Bozyiğit ve Madran, 2018) çocukların tüketici olarak sosyalleşmesi üzerinde doğrudan etkisi olduğunu tespit etmişlerdir.

\section{Akran Etkisi:}

Akran terimi, birbirlerini tanıyan, karşılıklı bilgi ve yaşam deneyimlerini paylaşan ve birbirleriyle karşılaştırma veya referans görevi gören bir grup üye olarak tanımlanmaktadır (Niu, 2013). Akranların genellikle benzer bir yaşta ve öğrenme evresinde olduğu ve sosyal statü ve bilişsel yetenek gibi birçok özelliği paylaştıkları varsayılmaktadır. Tüketici davranışı bakış açısından, akranların birey üzerindeki etkileri, bilgilendirici olması ve ürünler ve markalardan haberdar etmesi, bireylerin düşünce ve tutumlarını grubun tutumu ve davranışları ile karşılaştırma imkanı sağlaması ve bireyin tutum ve davranışlarının grup normlarına uyumunu sağlaması açısından önemlidir (Makgosa ve Mohube, 2007, s.64). Gençler bilgilendirici ve normatif kişilerarası etkilere çok daha duyarlıdır. Normatif etki, başka bir kişinin, grubun veya benliğin beklentilerine uyma baskısıdır. Bilgilendirici etki ise karar almak için diğer kaynaklardan gelen bilgilerin güvenilir, gerçeğe uygun ve kabul edilebilir olduğunu varsaymaktır (Mishra vd, 2018). Gençler normatif akran etkisi ile arkadaşlarının sosyal medyayı kullandıklarını gördüklerinde, çevrimiçi grubun bir parçası olmak için aynı platforma katılırlar (Hofstra, Corten, ve van Tubergen, 2016). Ergenlik dönemi insan yaşamında çok önemli bir aşamadır; burada kişi benzersiz bir kimlik geliştirmeye ve akranlar arasında arzu edilir bir sosyal imaj yaratmaya çalışır. Bu dönemde bir gruba ait olma veya kabul edilme isteği, gençlerin akran etkisi ile farklı davranışlar göstermesine yol açabilir.

Ebeveynlerin etkisi azaldıkça, akranların sosyalleşme süreci üzerindeki etkisinin yaşla birlikte arttığı tespit edilmiştir (Thomson ve Laing, 2003; Ward, 1974). Ürünlerin sembolik anlamlarını gençler arkadaşlarından öğrenmektedirler (Ateşoğlu ve Türkkahraman, 2009, s.221). Wang 
vd., (2012) gençlerin, akranlarından aldıkları çevrimiçi tavsiye veya bilgilerin güvenilir olduğunu düşündüklerini ve bu tavsiyelere önem verdiklerini tespit etmişlerdir. Meyer ve Anderson (2000, s.244), akran gruplarının, bireylerin kurallara uymasını sağlayarak ve bilgi vererek tüketim tercihlerini etkiledikleyerek sadece ne alınacağını değil, nasıl da alınacağını belirleyebildiklerini vurgulamaktadır. Moreau (2017), gençlerin özellikle teknoloji ürünlerinin ve hizmetlerinin akranları arasında "havalı" bir görüntü oluşturduğunu düşündüklerini belirtmiştir. $\mathrm{Bu}$ sebeple gençler sosyal medya ağlarında yer almaya çok daha istekli olabilmektedirler.

\section{Gençlerde Sosyal Medyaya Maruz Kalma:}

Sosyal medya, etkileşimleri, işbirliklerini ve içerik paylaşımını kolaylaştırmayı amaçlayan çevrimiçi uygulamalar, platformlar ve medyadır (Uyar, Oralhan ve Bayırbaş). Son yıllarda, cep telefonu ve iletişim teknolojisindeki önemli gelişmeler paylaşım, bilgiye erişim ve bilgi yaratma şeklini değiştirmiştir. Bu gelişmelerle sosyal ağlarda geçirilen zaman gittikçe artmıştır. İnsanlar zaman ve mekandan bağımsız olarak gerek tüketimle gerekse sosyalleşmeyle ilgili ihtiyaçlarını sosyal platformlar ve ağlarla karşılayabilmektedirler. Çoğu gencin okuldan kalan zamanının büyük bölümünü sosyal medya ağlarında geçirdiği tahmin edilmektedir. Sosyal medya, sürekli güncellenen dinamik yapısı, içerik oluşturma imkanı, iletişim kurma ve çoklu kullanıma uygun olması gibi özellikleri ile bireyleri etkisi altına almaktadır. Tüketici sosyalizasyonuna etki eden internet, tüketici davranışlarının değişmesini sağlamıştır (Südaş ve Töge, 2005, s.310).

Bradford (2004, s.2) sosyal medya kullanıcılarının çoğunluğunun 25 yaş altında olduğunu belirlemiştir. Çoğunlukla, gençler akranları arasında olumlu bir imaj oluşturmak için çevrimiçi içerik yayınlarlar (Oh ve LaRose, 2016). Bazen ebeveynler, çocuklarının güvenliğini ve iletişimde kalmalarını sağlamak için akıllı telefonlar gibi teknolojileri kullanmalarını onaylar ve teşvik ederler. Bu sayede internete erişme fırsatı da elde eden gençlerin sosyal medyayı kullanma olasılıkları artar. Südaş ve Töge'nin de belirttiği gibi, (2005) tüketici sosyalleşmesinin yeni bir değişkeni olarak sosyal ağlarda gerçekleşen akran iletişimi, tüketici karar 
verme süreci ve dolayısıyla pazarlama stratejileri üzerinde önemli bir etkiye sahiptir (Muratore 2008; Lueg ve Finney 2007; Wang, Yu ve Wei, 2012, Zhang ve Daugherty 2009). Südaş ve Töge, (2005) sosyal ağlarda gerçekleşen tüketim temelli akran iletişiminin, ürün ve hizmetlere yönelik tutumları ve bunun da satın alma niyetini artırdığı sonucuna ulaşmışlardır. Günümüzde televizyon ve internet, tüketicinin sosyalleşmesi sürecinde diğer kitle iletişim araçlarından daha etkili bir rol oynamaktadır (Garipova, 2007, s.21). Thaichon (2017, s.39) internetin, çocukların ve gençlerin çevrimiçi tüketiciler olarak yetkinliklerini kullanmalarına yardımcı olan iki yönlü iletişim kurma becerisi nedeniyle önemli bir sosyalleşme aracı olduğunu vurgulamaktadır.

\section{Metodoloji}

\section{Örneklem ve Veri Toplama Tekniği}

Araştırmanın evrenini Kayseri il merkezindeki orta öğretim kurumlarında eğitim gören öğrenciler oluşturmaktadır. MEB 2017 verilerine göre Kayseri ilinde orta öğretim kurumlarında eğitim gören toplam öğrenci sayısı 79.970 kişidir. Bununla birlikte Melikgazi, Kocasinan ve Talas ilçelerinde ise devlet okullarında 55.682 ve özel okullarda 8617 olmak üzere toplam 64.299 öğrenci eğitim görmektedir (MEB, 2018). Kocasinan, Melikgazi ve Talas merkez ilçelerinde yer alan ortaöğretim kurumlarında eğitim gören öğrencilere yüz yüze anket uygulanmıştır. Bu üç ilçenin seçilme sebebi konumları ve Kayseri ilinde toplam eğitim gören orta öğretim öğrencilerinin \% 80'inin bu ilçelerde olmasıdır. Örneklem tesadüfî olmayan örnekleme yöntemlerinden biri olan, kolayda örnekleme yönetimi ile tespit edilmiştir. Kolayda örnekleme ile hızlı ve ucuz yoldan veri elde edilebilmektedir (Nakip, 2006, s.204). Bu avantajları sebebiyle çalışmada bu yöntem tecih edilmiştir. Örneklem sayısı Yazıcı ve Erdoğan (2004) örneklem büyüklükleri tablosuna göre $\pm 0,05$ örnekleme hatası ile 380 olarak belirlenmiştir. 


\section{Veri Toplama Aracı}

Araştırmanın amaçları doğrultusunda hazırlanan anket formu gerekli açıklamaların yer aldığı bir üst yazı ve dört bölümden oluşmaktadır. Birinci bölümünde, katılımcıların sosyal medya kullanıp kullanmadıklarını tespit etmeye yönelik bir soru sorulmuştur. Bu soru ile sosyal medya kullanmayanları analiz dışı bırakmak amaçlanmıştır. İkinci bölümünde ise, tüketici olarak sosyalleşmesinde etkili olan aile (9 ifade), akran (10 ifade), sosyal medya (6 ifade) ve marka (4 ifade) değişkenlerine yönelik, değerlendirme yapabileceği 29 adet ifade yer almaktadır. Gençlerin medya kullanım davranışları da dahil olmak üzere çeşitli tüketici sosyalleşme ve pazar faktörlerine yönelik tutumlarını ve etkileşimlerini ölçmeye yönelik oluşturulan anket formu 5'li Likert tipi ölçek (1=kesinlikle katılmıyorum, 5=kesinlikle katılıyorum) ile hazırlanmıştır. Sonraki üçüncü bölümde ise, katılımcların internet ve sosyal medya kullanım davranışlarını (internet - sosyal medya kullanım sıklığı ve kullanım amacı, internete bağlandığı araçlar vb.) tespit etmek amacıyla hazırlanmış sorular yer almaktadır. Dördüncü ve son bölümde ise, cinsiyet ve yaştan oluşan demografik özelliklerin tespitine yönelik sorular bulunmaktadır.

Anket formu, literatürde geçerlik ve güvenirlikleri test edilmiş ölçeklerden yararlanılarak çalışmaya uyarlanmıştır. Kullanılan ölçekler Dotson ve Hyatta'nın (2005) çalışmalarından Türkçeye çevrilerek elde edilmiştir. Sadece orjinal çalışmada televizyonun etkisine yönelik oluşturulan ifadeler sosyal medyaya uyarlanmıştır. Veri toplamaya başlamadan önce yapılan pilot çalışmada, kolayda örnekleme yolu ile seçilen 20 orta öğretim öğrencisine anket taslağı uygulanmıştır. Bu çalışma ile ölçeklerde çeviri kaynaklı veya diğer sebeplerden oluşabilecek muh-temel problemlerin önlemesi amaçlanmıştır. Yürütülen pilot çalışma sonrasında anket formu cevaplayıcı genç kitlenin net olarak anlayabileceği ve rahatlıkla cevaplayabileceği şekilde tekrardan düzenlenerek son hali verilmiştir. Anketlerin eksiksiz ve doğru bir şekilde cevaplanması için katılımcılara gerekli açıklamalar yapılmıştır. Katılımı arttırmak amacıyla öğrencilerden cinsiyet ve yaş dışında demografik bilgi veya kimlik bilgisi istenmemiştir. Anketler incelenmiş, analize uygun olmayan eksik, tutarsız ve hatalı olduğu tespit edilen veriler ayıklanmıştır. Bu işlemler sonucunda toplam 
kullanılabilir anket sayısı 347 adet olmuştur. Elde edilen veriler SPSS 22 paket programı ile analiz edilmiştir.

Araştırmada kullanılan ölçeklerin güvenilirliği Cronbach's Alpha katsayısı kullanılarak hesaplanmıştır. Ölçekteki değişkenlerin Cronbah's Alpha değerlerinin 0,717- 0,873 arasında olduğu görülmektedir (Aile $\alpha=0,754$, akran $\alpha=0,717$, marka $\alpha=0,873$, sosyal medya $\alpha=0,788$ ). Alpha değerinin $0,60 \leq \alpha \leq 0,80$ olması ölçeğin oldukça güvenilir olduğunu ve $0,80 \leq \alpha<1,00$ olması ise ölçeğin yüksek derecede güvenilir olduğunu göstermektedir (Kalaycı, 2014, s.405). Bu sonuçları ölçeklerin güvenilir olduğunu ve analizlerde kullanılabileceğini gösterir. Ölçekteki değişkenlerin ortalamalarına bakıldığında katılımcılar aile 3.18, akran 2.77, marka 3.07 ve sosyal medya değişkenlerine 3.17 ortalamalarla katılmışlardır.

\section{Araştırmanın Amacı ve Hipotezleri}

Araştırmanın amacı, sosyal medyaya maruz kalma ve cinsiyete göre tüketici sosyaleşme aracılarının (aile, akran, marka, sosyal medya) farklılık gösterip göstermediğini tespit etmektir.

$H_{0}$ : Tüketici sosyaleşme aracılarından aile etkisinde katılımcıların cinsiyetlerine göre istatistiksel olarak anlamlı bir farklılık yoktur.

H1.1: Tüketici sosyaleşme aracılarından aile etkisinde katılımcıların cinsiyetlerine göre istatistiksel olarak anlamlı bir farklılık vardır.

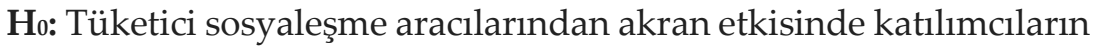
cinsiyetlerine göre istatistiksel olarak anlamlı bir farklılık yoktur.

H2.1: Tüketici sosyaleşme aracılarından akran etkisinde katılımcların cinsiyetlerine göre istatistiksel olarak anlamlı bir farklılik vardir.

Ho: Tüketici sosyaleşme aracılarından marka etkisinde katılımcıların cinsiyetlerine göre istatistiksel olarak anlamlı bir farklilık yoktur.

H3.1: Tüketici sosyaleşme aracılarından marka etkisinde katılımcların cinsiyetlerine göre istatistiksel olarak anlamlı bir farklılık vardır.

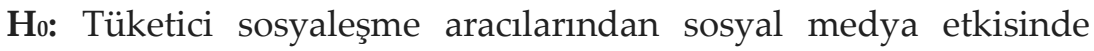
katılımcların cinsiyetlerine göre istatistiksel olarak anlamlı bir farklılık yoktur. 
H4.1: Tüketici sosyaleşme aracılarından sosyal medya etkisinde katılımciların cinsiyetlerine göre istatistiksel olarak anlamlı bir farklılık vardır.

$H_{0}$ : Tüketici sosyaleşme aracılarından aile etkisinde katılımcıların sosyal medyaya maruz kalma düzeyine göre istatistiksel olarak anlamlı bir farklılık yoktur.

H5.1: Tüketici sosyaleşme aracilarından aile etkisinde katılımcıların sosyal medyaya maruz kalma düzeyine göre istatistiksel olarak anlamlı bir farklılık vardır.

$H_{0}$ : Tüketici sosyaleşme aracılarından akran etkisinde katılımcıların sosyal medyaya maruz kalma düzeyine göre istatistiksel olarak anlamlı bir farklılık yoktur.

H6.1: Tüketici sosyaleşme aracılarından akran etkisinde katılımciların sosyal medyaya maruz kalma düzeyine göre istatistiksel olarak anlamlı bir farklılık vardır.

Ho: Tüketici sosyaleşme aracılarından marka etkisinde katılımcların sosyal medyaya maruz kalma düzeyine göre istatistiksel olarak anlamlı bir farklılık yoktur.

H7.1: Tüketici sosyaleşme aracılarından marka etkisinde katılımcların sosyal medyaya maruz kalma düzeyine göre istatistiksel olarak anlamlı bir farklılık vardır.

Ho: Tüketici sosyaleşme aracılarından sosyal medya etkisinde katılımcıların sosyal medyaya maruz kalma düzeyine göre istatistiksel olarak anlamlı bir farklılık yoktur.

H8.1: Tüketici sosyaleşme aracılarından sosyal medya etkisinde katılımcların sosyal medyaya maruz kalma düzeyine göre istatistiksel olarak anlamlı bir farklılık vardır.

\section{Bulgular}

Araştırmada elde edilen verilerin öncelikle frekans ve yüzde oranlarını gösteren tablolar oluşturulmuş ve daha sonra da testi uygulanmıştır. Katılımcıların cinsiyet ve yaştan oluşan demografik bilgileri aşağıda yer alan Tablo 1' de gösterilmektedir.

Araştırmada yer alan katılımcların \%39,5'i kız ve \%60,5'i erkeklerden oluşmaktadır. Ankete cevap veren kişilerin cinsiyetleri bakımından 
homojen bir kütle oluşturdukları görülmektedir. Katılımcıların \%21,3'ünün 15 yaşında, \%30,5'inin 16 yaşında, \%30'unun 17 yaşında ve $\% 18,2$ 'sinin 18 yaşında olduğu görülmektedir. Katılımcıların \%35,2'si özel okul öğrencisiyken \%64,8'i devlet okulu öğrencisidir. Evren içinde de özel okul öğrencileri devlet okulu öğrencilerine göre sayıca az olduğu için bu dağılım kabul edilebilmektedir.

Tablo 1. Katılımcıların Demografik Özelliklere Göre Dağılımı

\begin{tabular}{lccc}
\hline \multicolumn{1}{r}{ Cinsiyet } & f & \% \\
\hline Kiz & 137 & 39,5 \\
Erkek & 210 & 60,5 \\
\hline \multicolumn{2}{c}{ Okul Türü } & f & \% \\
\hline Devlet & 225 & 64,8 \\
Özel & Yaş & 122 & 35,2 \\
\hline \multicolumn{2}{r}{} & f & \% \\
\hline 15 & 74 & 21,3 \\
16 & 106 & 30,5 \\
17 & 104 & 30 \\
18 & 63 & 18,2 \\
\hline Toplam & $\mathbf{3 4 7}$ & $\mathbf{1 0 0}$ \\
\hline
\end{tabular}

Katılımcıları sosyal medya kullanımı ile ilgili sorulara verdikleri cevapların dağılımı aşağıda yer alan Tablo 2-4'de görülmektedir.

Katılımcıların \%61,4 gibi büyük bir oranı her gün sosyal ağları kullandığını belirtmiştir. \%1,2'si haftada 3-4 gün, \%34,4'ü haftada 2 gün, $\% 1,4^{\prime}$ ü haftada1 ve \%0,6'sı ise ayda 1-2 gün sosyal ağları kullandığını belirtmişlerdir.

Tablo 2. Katılımcıların Sosyal Medya Kullanım Sıklı̆̆

\begin{tabular}{lcc}
\hline \multicolumn{1}{c}{ Sosyal medya kullanım sıklığ } & f & \% \\
\hline Her gün & 213 & 61,4 \\
Haftada 3-6 gün & 4 & 1,2 \\
Haftada 2 gün & 123 & 34,4 \\
Haftada 1 & 5 & 1,4 \\
Ayda 1-2 gün & 2 & 0,6 \\
Toplam & $\mathbf{3 4 7}$ & $\mathbf{1 0 0}$ \\
\hline
\end{tabular}

Katılımciların \%8,65'i her girdiklerinde ortalama 1 saatten az, \%39,8'i 1-2 saat, $\% 27,1^{\prime}$ i 3-5 saat ve $\% 23,3^{\prime}$ ü de $6-7$ saat ve $\% 1,2^{\prime}$ si 7 saatten fazla sosyal medyada kaldığını belirtmiştir. 
Tablo 3. Katılımcılarn Sosyal Medyada Ortalama Harcadıkları Süre

\begin{tabular}{lcc}
\hline \multicolumn{1}{c}{ Sosyal Medyada Harcanan Zaman } & f & \% \\
\hline 1 saatten az & 30 & 8,6 \\
1-2 saat & 138 & 39,8 \\
3-5 saat & 94 & 27,1 \\
6-7 saat & 81 & 23,3 \\
7 saatten fazla & 4 & 1,2 \\
Toplam & $\mathbf{3 4 7}$ & $\mathbf{1 0 0}$ \\
\hline
\end{tabular}

Aşağıda yer alan Tablo 4'te görüldüğü gibi katılımcıların büyük bir kısmı sosyal medyayı, paylaşımda bulunmak \%37,18, \%16,71'i eğlence, $\% 12,10^{\prime}$ u arkadaşları, \%10,66's1 merak ve \%9,51'i iletişim kurmak için kullandıkların belirtmiştir. Geri kalanlar ise bilgi $(\% 6,92)$ haber alma $(\% 2,59)$ ve diğer $(\% 4,32)$ amaçlarla sosyal medyayı kullandıklarını belirtmiştir.

Tablo 4. Katılımcılarn Sosyal Medya Kullanım Amact

\begin{tabular}{lcc}
\hline \multicolumn{1}{c}{ Sosyal medya kullanım amacı } & $\mathbf{f}$ & $\mathbf{\%}$ \\
\hline Paylaşım & 129 & 37,18 \\
Eğlence & 58 & 16,71 \\
Arkadaşlar & 42 & 12,10 \\
Merak & 37 & 10,66 \\
İletişim & 33 & 9,51 \\
Bilgi & 24 & 6,92 \\
Diğger & 15 & 4,32 \\
Haber & 9 & 2,59 \\
Toplam & $\mathbf{3 4 7}$ & $\mathbf{1 0 0}$ \\
\hline
\end{tabular}

Tüketici Sosyaleşme Aracıları Etkisinin Cinsiyete Göre Farklılaşma Durumu

Tüketici sosyaleşme aracilarının etkisinin cinsiyete göre farklılık gösterip göstermediğini belirlemek amacıyla bağımsız gruplar için $t$ testi analizi yapılmıştır. Analize ilişkin bulgular Tablo 5 'te verilmiştir.

Tablo 5 incelendiğinde sosyalleşme aracılarından sosyal medya ve marka etkisinde cinsiyete göre istatistiksel olarak anlamlı bir farklılık yoktur. $\mathrm{Bu}$ durumda $\mathrm{H}_{1.1}$ ve $\mathrm{H}_{2.1}$ hipotezleri reddedilmiştir.

Sosyalleşme aracılarından akran etkisinde kızların ortalamasının 2,98 ve erkeklerin ortalamasının ise 2,64 oranında değer gösterdiği 
görülmektedir. Grupların almış oldukları puan ortalamaları arasındaki farkın anlamlı olup olmadığını test etmek amacıyla hesaplanan $t$ değeri $(\mathrm{t}=2,612 ; \mathrm{p}<, 05)$ gruplardaki puan farkının ,05 düzeyinde anlamlılık gösterdiğini ifade etmektedir. Bu bulguya göre akran etkisi kızlarda erkeklerden anlamlı düzeyde yüksektir.

Sosyalleşme aracılarından aile etkisinde kızların ortalamasının 3,49 ve erkeklerin ortalamasının ise 3,17 oranında değer gösterdiği görülmektedir. Grupların almış oldukları puan ortalamaları arasındaki farkın anlamlı olup olmadığını test etmek amaciyla hesaplanan $t$ değeri $(t=4,192 ; p<, 01)$ gruplardaki puan farkının, 01 düzeyinde anlamlılık gösterdiğini ifade etmektedir. Bu bulguya göre aile etkisi kızlarda erkeklerden anlamlı düzeyde yüksektir.

Tablo 5. Sosyaleşme Aracıları Etkisinin Cinsiyete Göre Farklılaşmasına İlişkin t Testi Sonuçları

\begin{tabular}{|c|c|c|c|c|c|c|}
\hline Aracılar & Cinsiyet & $\mathbf{n}$ & $\overline{\mathrm{X}}$ & ss. & $\mathbf{t}$ & $p$ \\
\hline \multirow{2}{*}{ Sosyal Medya } & $\mathrm{K}_{1 \mathrm{Z}}$ & 127 & 3,1275 & 62856 & ,304 & ,761 \\
\hline & Erkek & 210 & 3,0878 & ,78478 & & \\
\hline \multirow{2}{*}{ Akran } & $\mathrm{K} 1 \mathrm{z}$ & 127 & 2,9822 & ,78322 & 2,612 & 010 \\
\hline & Erkek & 210 & 2,6455 & 68265 & & \\
\hline \multirow{2}{*}{ Aile } & $\mathrm{K}_{1 \mathrm{Z}}$ & 127 & 3,5840 & 1,01607 & 4,192 & ,000 \\
\hline & Erkek & 210 & 2,8988 & ,71397 & & \\
\hline \multirow[b]{2}{*}{ Marka } & $\mathrm{K}_{1 z}$ & 127 & 2,8265 & 86483 & $-1,063$ & 290 \\
\hline & Erkek & 210 & 2,9940 & 88322 & & \\
\hline
\end{tabular}

Tüketici Sosyaleşme Aracıları Etkisinin Sosyal Medyaya Maruz Kalma Düzeyine Göre Farklılaşma Durumu

Tüketici sosyaleşme aracılarının etkisinin sosyal medyaya maruz kalma düzeyine göre farklılık gösterip göstermediğini belirlemek amacıyla bağımsız gruplar için t testi analizi yapılmıştır. Analize ilişkin bulgular Tablo 6'da verilmiştir.

Tablo 6 incelendiğinde sosyalleşme aracılarından akran ve aile etkisinde sosyal medyaya maruz kalma düzeylerine göre istatistiksel olarak anlamlı bir farklılık yoktur. Bu durumda $\mathrm{H}_{5.1}$ ve $\mathrm{H}_{6.1}$ hipotezleri reddedilmiştir. 
Tablo 6. Sosyaleşme Aracılan Etkisinin Sosyal Medyaya Maruz Kalmaya Göre Farklılaşmasına İlişkin t Testi Sonuçları

\begin{tabular}{|c|c|c|c|c|c|c|}
\hline Aracilar & $\begin{array}{c}\text { Sosyal Medyaya Maruz } \\
\text { Kalma Düzeyi }\end{array}$ & $\mathrm{n}$ & $\bar{X}$ & ss. & $t$ & $\mathbf{p}$ \\
\hline Sosyal & Düşük & 130 & 2,5500 & 62856 & $-2,637$ & ,009 \\
\hline Medya & Yüksek & 217 & 3,1615 & 78478 & & \\
\hline \multirow{2}{*}{ Akran } & Düşük & 130 & 2,5222 & 78322 & $-1,063$ & ,290 \\
\hline & Yüksek & 217 & 2,7833 & 68265 & & \\
\hline \multirow{2}{*}{ Aile } & Düşük & 130 & 3,4900 & 1,01607 & 1,067 & ,288 \\
\hline & Yüksek & 217 & 3,1692 & ,71397 & & \\
\hline \multirow{2}{*}{ Marka } & Düşük & 130 & 2,3000 & 86483 & $-2,394$ & ,018 \\
\hline & Yüksek & 217 & 2,9874 & 88322 & & \\
\hline
\end{tabular}

Sosyalleşme aracılarından sosyal medya etkisinde sosyal medyaya maruz kalma düzeyleri düşük olan katılımcıların ortalamasının 2,55 ve yüksek olanların ortalamasının ise 3,16 oranında değer gösterdiği görülmektedir. Grupların almış oldukları puan ortalamaları arasındaki farkın anlamlı olup olmadığını test etmek amacıyla hesaplanan $t$ değeri $(\mathrm{t}=-2,637 ; \mathrm{p}<, 01)$ gruplardaki puan farkının ,01 düzeyinde anlamlılık gösterdiğini ifade etmektedir. Bu bulguya göre sosyal medyanın etkisi, sosyal medyaya yüksek oranda maruz kalanlarda anlamlı düzeyde yüksektir.

Sosyalleşme aracilarından marka etkisinde sosyal medyaya maruz kalma düzeyleri düşük olan katılımcıların ortalamasının 2,30 ve yüksek olanların ortalamasının ise 9,98 oranında değer gösterdiği görülmektedir. Grupların almış oldukları puan ortalamaları arasındaki farkın anlamlı olup olmadığını test etmek nedeniyle hesaplanan $t$ değeri $(t=-2,394 ; p<, 05)$ gruplardaki puan farkının, 05 düzeyinde anlamlılık gösterdiğini ifade etmektedir. Bu bulguya göre markanın etkisi, sosyal medyaya yüksek oranda maruz kalanlarda anlamlı düzeyde yüksektir.

\section{Tartışma}

Bu çalışmada sosyal medyaya maruz kalma düzeyi ve cinsiyete göre aile, akran, marka, sosyal medyadan oluşan tüketici sosyalleşme aracılarının farklılık gösterip göstermediğinin ortaya konması planlanmıştır. Bu amaç çerçevesinde veri toplamak amaciyla hazırlanan anket formu Dotson 
ve Hyatta (2005) tarafından geliştirilen ölçek maddelerinden yararlanılarak hazırlanmıştır.

Yapilan analizler sonucunda ergenlerin sosyal medya kullanım alışkanlıkları ile ilgili verilere ulaşılmıştır. Gençlerin \%61,4 gibi büyük bir oranı her gün ve \%34,4'ü ise haftada 2 gün sosyal ağları kullandığını belirtmiştir. Günümüz gençleri için internet vazgeçilmez bir unsurdur. Pek çok kaynakta bu jenerasyon tanımlanırken internet çocukları olarak adlandırılmaktadır. Bu sebeple her gün kullananların oranının yüksek çıkması beklenen bir sonuçtur. Haftada 2 gün kullananların oranının yüksek çıkma sebebi ise, örnek kitlenin üniversite sınav hazırlı̆̆ recinde olmasına bağlanabilir. Bu sebeple gençlerin internet kullanımı aileleri tarafından kısıtlanmış ve muhtemelen sadece hafta sonu kullanımına izin verilmiş olabilir. Ayrıca gençlerin sosyal medyada kalış süreleri incelendiğinde hafta içi sosyal medya kullananların okuldan kalan zamanlarının büyük bölümünü sosyal medyada geçirdikleri düşünülebilir. $\mathrm{Bu}$ da dijital bağımlılık açısından konunun ele alınabileceğini düşündürmektedir. Gençler için sosyal medyanın paylaşımda bulunmak $(\% 37,2)$ demek olduğu rahatlıkla söylenebilir. Özellikle instagram ve facebook gibi sosyal ağlarda paylaşımda bulunmak gençler için son derece önemlidir.

Çalı̧̧mada, tüketici sosyalleşme sürecinde akran ve aile etkisinin cinsiyete göre farklılık gösterdiği tespit edilmiştir. Elde edilen sonuçlara göre tüketici sosyalleşme sürecinde kızlarda akran ve aile etkisi daha yüksektir. Türk toplumunun sosyal yapısından dolayı kız çocukları üzerinde ailenin daha çok etkili olması mümkündür. Dotson ve Hyatta (2005) çeşitli sosyal etki kaynaklarının göreceli etkilerinin cinsiyete göre değiştiğini kızların, kişisel olan aile ve arkadaşlarla olan etkileşimlerden, erkeklerin ise kişisel olmayan iletişimden daha çok etkilendiklerini tespit etmiştir. Sonuçlar bu çalışmanın bulguları ile uyumludur. Ayrıca cinsiyet açısından marka ve sosyal medya aracılarının farklılık göstermediği de çalışmanın bulguları arasındadır.

Sosyalleşme aracılarından akran ve aile etkisinde sosyal medyaya maruz kalma düzeylerine göre bir farklılık olmadığı görülmüştür. Sosyalleşme aracılarından sosyal medyanın etkisinin, sosyal medyaya yüksek oranda maruz kalanlarda anlamlı düzeyde yüksek olduğu görülmüştür. Bu beklenen bir sonuçtur. Sosyal medya değişkenini ölçmek için 
hazırlanan sorular düşünülürse "Sosyal medyada yer almak havalıdır", "Sosyal medya hayatımın önemli bir parçasıdır" ve "Sosyal medyadan pek çok şey öğreniyorum" gibi ifadelere katılan bireylerin sosyal medyaya daha çok maruz kalması muhtemeldir. Bu bulguya göre markanın etkisi, sosyal medyaya yüksek oranda maruz kalanlarda anlamlı düzeyde yüksektir. Sosyal medyayı daha çok takip eden ergenlerin bu mecralarda yayınlanan reklamlara daha fazla maruz kalması olasıdır. Ayrıca sosyal medyayı daha çok takip eden ergenler farklı etkileyici gruplarla veya kişilerle daha çok temas halinde olabilirler (bloggerlar, ünlü kişiler vb.). Özellikle sosyal ağlar üzerinden ünlüleri ve pek çok moda markasını takip etmek mümkündür. Bu gibi sebeplerle sosyal medyaya daha fazla maruz kalan ergenlerin üzerinde marka etkisinin daha fazla olması beklenilebilir.

Her araştırmada olduğu gibi bu araştırmada da bir takım sınırlılıklar bulunmaktadır. Araştırmanın en önemli sınırlılığı seçilen örnek kütle ve araştırmanın kapsamıyla ilgilidir. Bu araştırma, zaman ve maliyet kısıtlarından dolayı sadece Melikgazi, Kocasinan ve Talas olmak üzere Kayseri'nin üç ilçesinde yürütülmüştür. Gelecek çalışmalarda daha kapsamlı ve farklı örneklemlerde yapılabilir. Çalışmada tesadüfi olmayan örnekleme yöntemlerinden kolayda örnekleme yönteminin kullanılması ise bir başka kısıtı oluşturmaktadır. Tesadüfi örneklemenin yapılmamış olması nedeniyle bulgularla ilgili genellemeler yapılırken dikkatli olunmalıdır. Araştırmanın bir diğer sınırlılığı araştırmanın kapsamıla ilgilidir. Sosyalleşme aracılarından sadece aile, akran, marka ve sosyal medya kavramları dikkate alınmıştır. Ayrıca bu aracılar üzerinde pek çok faktör etkili olabilecekken sadece sosyal medyaya maruz kalma ve cinsiyet çalışmaya dahil edilmiştir. Gelecekteki çalışmalarda mağaza, ambalaj vb. başka aracıları da çalışma kapsamına eklenebilir. Çalışmanın bir diğer sınırı da sadece ergenler açısından konunun incelenmesidir. Ergenler sosyal etkilere daha açık olabileceği için seçilmiştir. Literatürde daha küçük yaşta çocuklar açısından da benzer çalışmalar yer almaktadır. İleride yapılacak çalışmalarda çocuk ve ergenler bir arada çalışılarak özellikle yaşın sosyalleşme üzerindeki etkisi de incelenebilir. Son olarak, gelecekte sosyal medya etkisi incelenirken dijital bağımlılık kavramı da konuya dahil edilebilir. 


\title{
EXTENDED ABSTRACT
}

\section{The Impact of Social Media on Youth Socialization}

\author{
Kumru Uyar \\ Nuh Naci Yazgan University
}

The rapid increase in social media use paved the way for social media to be defined as a new marketing tool. Social media advertising has become an important part of the media mix. With this new channel, businesses can reach consumers directly and by personalizing at a lower cost. For this reason, social media can be defined as a fairly new and powerful marketing channel that businesses have achieved in reaching their potential customers. Thus, social media is an effective tool in the socialization process as a consumer. The dynamics of the children and the young market have been striking nowadays. In addition to family, peers and traditional media, which are the traditional sources of information for young people and affect consumption decisions, social media networks have gained importance. Human computer interaction ( $\mathrm{HCI}$ ) feature attracts children and young people with ease of use and exciting appearance of high socio-technologies. Children and young people who can easily use social media with HCI-enabled technologies can socialize easily on social media platforms such as Youtube, Facebook and Instagram and they can be strong potential consumers against the advertisements they see on these platforms. Consumer socialization process has become very different nowadays due to the increase of internet usage, differentiation of social media and media usage and sociological changes in family structure. In this respect, it is suggested that more recent researches on consumer socialization processes should be made to revise their traditional assumptions (Dotson and Hyatt, 2005, p.36). The connection of young people with social media is undeniable. Today, young people can meet their social and consumption needs through social media. Social media is almost a part of their daily lives. In this respect, it is an important problem to determine whether social media affects the socialization of young people as consumers. In the context of marketing, Ward (1974, p.2) defines consumer 
socialization as the processes of gaining skills, knowledge and attitudes related to the existence of young people as consumers in the market. The aim of this article is to determine whether consumer socialization agents (family, peer, brand and social media) differ according to social media exposure and gender. Since adolescents may be more open to social impacts, the study was applied to secondary school students. The scales used in the study were adapted from Dotson and Hyatta (2005) studies. The questionnaire form, which was prepared to measure the attitudes and interactions of various young people about various consumer socialization and market factors including media usage behaviors, was prepared with 5-point Likert-type scale $(1=$ strongly disagree, $5=$ strongly agree $)$. Adolescence is the most important time in socialization (Niu, 2013). Therefore, the study was limited to only secondary school students.

The data were collected from 347 participants selected by means of sampling method. SPSS 22 package program was used in the analysis. The reliability of the scales used in the study was calculated using Cronbach's Alpha coefficient. The Cronbach Alpha values of the variables in the scale ranged from 0,717 to 0,873 (Family $\alpha=0,754$, peer $\quad \alpha=0,717$, brand $\alpha=$ 0,873 , social media $\alpha=0,788$ ). These results indicate that the scales are reliable and can be used in the analysis. As a result of the analyzes, data about the social media usage habits of adolescents were reached. $61.4 \%$ of youth stated that they use social networks every day and $34.4 \%$ of them use social networks 2 days a week. When the length of stay of social media is examined, it can be thought that young social media users spend most of their time on social media during the week. It can easily be said that social media for young people means sharing (37.2\%). Especially, social networks like Instagram and Facebook are very important for young people to share. When we look at the averages of the variables in the scale, family (3.18) and social media (3.17) are the variables that young people stated that they are under the influence of the most. Peer (2.77) and brand (3.07) variables are low in terms of the effect on the expression. In the study, it was determined that peer and family effects differed according to gender in consumer socialization process. According to the results, the peer and family effects of girls are higher in consumer socialization process. Dotson and Hyatta (2005) found that the relative effects of various social sources of influence vary by gender, and that girls are more affected 
by personal interactions such as family and friends, while males are more affected by non-personal communication. The results were consistent with the findings of this study. In addition, gender and brand and social media mediators did not differ among the findings of the study. It was seen that there was no difference between socialization agents and peer and family effect according to social media exposure levels. The effect of social media, which is one of the socialization tools, was significantly higher in those exposed to social media. This is an expected result. Considering the questions prepared to measure the social media variable, it is likely that individuals who participate in such statements as "It's cool to be on social media", "Social media is an important part of my life" and "I learn a lot from social media" are more likely to be exposed to social media. According to this finding, the effect of the brand is significantly higher in those exposed to social media at high rates. Adolescents who follow more social media are more likely to be exposed to advertisements published in these media. In addition, adolescents who are more likely to follow social media may have more contact with different groups of influencers or people (bloggers, celebrities etc.). It is possible to follow celebrities and many fashion brands especially through social networks. For these reasons, it may be expected that the effect of brand on adolescents who are exposed to social media is higher. The study is expected to contribute to the literature by updating the main findings in the literature of consumer socialization agents such as family, peer, brand and social media and providing empirical information to explain how the consumer socialization process works in today's youth.

\section{Kaynakça / References}

Ateşoğlu, İ., Türkkahraman, M. (2009). Çocukların tüketici olarak sosyalleşmesi. Süleyman Demirel Üniversitesi İktisadi ve İdari Bilimler Fakültesi Dergisi, 14(3), 215-228.

Bandura, A. (1978). Social learning theory of aggression. Journal of Communication, 28(3), 12-29. 
Basu, R. ve Sondhi, N. (2014). Child socialization practices: Implications for retailers in emerging markets. Journal of Retailing and Consumer Services, 21(5), 797-803.

Bozyiğit, S. ve Madran, C. (2018). Çocukların çevre bilinçli tüketici olarak sosyalleşmesinde annelerin çocuk yetiştirme tutumlarının rolü. Manas Sosyal Araştırmalar Dergisi, 7(2), 173-196.

Carlson, L., ve Grossbart, S. (1988). Parental style and consumer socialization of children. Journal of consumer research, 15(1), 77-94.

Cowell, P. (2001). Marketing to children: a guide for students and practitioners-Part 2. The Marketing Review, 2(1), 71-87.

Dal, N. ve Dal, V. (2015). Çocukların tüketici olarak sosyalleşme sürecinde tv reklamlarının ve ailenin rolü hakkında teorik bir çalışma. Mehmet Akif Ersoy Üniversitesi Sosyal Bilimler Enstitüsü Dergisi, 1(13), 371-388.

Dotson, M. J. ve Hyatt, E. M. (2005). Major influence factors in children's consumer socialization. Journal of Consumer Marketing, 22 (1), 3542.

Dursun, Y. (1993). Gençlerin tüketicilik rolünü kazanmaları. Yayınlanmamış Doktora Tezi, Erciyes Üniversitesi, Kayseri.

Fan, Y. ve Li, Y. (2010). Children's buying behaviour in China: A study of their information sources. Marketing Intelligence ve Planning, 28(2), 170-187.

Garipova, C. (2007). Gençlerin tüketici olarak sosyalleşmesi ve tataristan'da bir araştırma. Yayınlanmamış Yüksek Lisans Tezi, Erciyes Üniversitesi, Kayseri.

Harris, F., Gordon, R., MacKintosh, A. M., ve Hastings, G. (2015). Consumer socialization and the role of branding in hazardous adolescent drinking. Psychology ve Marketing, 32(12), 1175-1190. doi:10.1002/mar.20842.

Haynes, J. L., Burts, D. C., Dukes, A., ve Cloud, R. (1993). Consumer socialization of preschoolers and kindergartners as related to clothing consumption. Psychology ve Marketing, 10(2), 151-166.

Hofstra, B., Corten, R. ve van Tubergen, F. (2016). Who was first on Facebook? Determinants of early adoption among adolescents. New Media ve Society, 18(10), 2340-2358. 
Lueg, J. E., ve Finney, R. Z. (2007). Interpersonal communication in the consumer socialization process: Scale development and validation. Journal of Marketing Theory and Practice, 15(1), 25-39.

Madran, C., ve Bozyiğit, S. (2013). Çocukların tüketici olarak sosyalleşme süreci. Cag University Journal of Social Sciences, 10(1), 71-96.

Mishra, A., Maheswarappa, S. S., Colby, C. L. (2018). Technology readiness of teenagers: a consumer socialization perspective, Journal of Services Marketing, https://doi.org/10.1108/JSM-07-2017-0262.

Moschis, G.P. ve Churchill, G.A. (1978). Consumer socialization: theoretical and empirical analysis. Journal of Marketing Research, 15, 599609.

Moschis, G.P., Moore, R.L., ve Smith, R.B. (1984). The impact of family communication on adolescent consumer socialization, Advances in Consumer Research, 11(1), 314-319.

Nakip M. (2006). Pazarlama araştırmaları (Teknikler ve (SPSS Destekli) Uygulamalar) 2. Baskı, Ankara: Seçkin Yayınevi.

Niu, H.J. (2013) Cyber peers' influence for adolescent consumer in decision-making styles and online purchasing behavior, Journal Applied Social Psychology, 43(6), 1228-1237.

Südaş, H. D., ve Töge, B. (2015). Sosyal ağlarda tüketim temelli akran iletişiminin incelenmesi: adana ilinde bir uygulama. Akademik Sosyal Araştırmalar Dergisi, 3(15), 309-327.

Thaichon, P. (2017). Consumer socialization process: The role of age in children's on line shopping behavior. Journal of Retailing and Consumer Services, 34, 38-47.

Oh, H. J., ve LaRose, R. (2016). Impression management concerns and support-seeking behavior on social network sites. Computers in human behavior, 57, 38-47.

Uyar K., Güllü K., ve Erkan M. (2015). The role of Turkish youth in family purchase decision. Organisational Studies and Innovation Review, 1(1), 81-88.

Uyar, K., Oralhan, B., ve Bayırbaş, İ. V. (2019). Marka değeri en yüksek 100 türk markasının sosyal medya kullanımları üzerine bir inceleme. Erciyes İletişim Dergisi, 6 (1), 287-306. 
Vijayalakshmi, A., Lin, M. H., ve Laczniak, R. N. (2018). Managing Children's Internet Advertising Experiences: Parental Preferences for Regulation. Journal of Consumer Affairs, 52(3), 595-622.

Wang, X., Yu, C., ve Wei, Y. (2012). Social media peer communication and impacts on purchase intentions: A consumer socialization framework. Journal of interactive marketing, 26(4), 198-208.

Ward, S. (1974). Consumer socialization. Journal of Consumer Research, 1(2), 1-14.

Zhang, J., ve Daugherty, T. (2009). Third-person effect and social networking: implications for online marketing and word-of-mouth communication. American Journal of Business, 24(2), 53-64.

\section{Kaynakça Bilgisi / Citation Information}

Uyar, K. (2019). Gençlerin tüketici olarak sosyalleşmesinde sosyal medyanın etkisi. OPUS-Uluslararası Toplum Araştırmaları Dergisi, 10(17), 1544-1567. DOI: 10.26466/opus.535049 